\title{
A study of leprosy and other skin diseases in school children in the state of Amazonas, Brazil
}

\author{
*S TALHARI, MARIA A A TORRECILA \\ \& ANETTE C TALHARI
}

Centro de Dermatologia Tropical e Venereologia 'Alfredo da Matta', Faculty of Medicine, University of Amazonas and Secretaria de Estado de Saude, Estado do Amazonas, Brazil.

Accepted for publication 15 August 1987

\begin{abstract}
Summary During the period 1979-1982, 100, 939 school children were examined for leprosy and other skin diseases. One hundred and seven cases of leprosy were discovered, 16 with lepromatous type, 12 with indeterminate type, 11 with borderline and 68 with tuberculoid type. The most frequent skin diseases found were dermatozoonosis, superficial mycosis, pyoderma, warts, pytiriasis alba and naevus.
\end{abstract}

\section{Introduction}

According to official statistics, of all the Brazilian states, the state of Amazonas has the largest leprosy endemic problem, i.e. 12 patients per thousand.

In December 1979 there were 10,800 cases of leprosy registered in the state of Amazonas of which 1744 were under 14 years of age. Based on these findings and the experience of other studies, ${ }^{1,2,6,7,9,10}$ we decided to include a dermatological examination of school children as part of the leprosy control programme.

\section{Methods}

The school children examined live in Manaus, the capital, and the interior of the state of Amazonas and belong to the poorer classes of the population.

The dermatological examination was carried out by 8 people, who had no previous knowledge of dermatology, and one dermatologist.

* Department of Public Health 
The study was done in two stages and was carried out during 1979-82. During the first stage, the future paramedical workers did a dermatological examination of a small group of school children and those with dermatological lesions were examined by the dermatologist. This examination was carried out in the school and the paramedical workers (PMW) were instructed on the different dermatological problems likely to be encountered. At the end of the first month the PMWs were capable of identifying the dermatological problems, which occurred most frequently such as superficial mycosis, pitiriasis alba, zoodermatosis and suspected leprosy. The Madrid classification was used for identifying leprosy. After two months the second stage began. This involved a weekly meeting of PMW with the dermatologist during which time only suspected leprosy cases and those cases without a definite diagnosis were examined. These patients were examined by all the PMWs after which the diagnoses were discussed. Those children who needed biopsies or other examinations were sent to the outpatients clinic.

The cases of leprosy were confirmed by bacilloscopy and histopathology. Histopathology was carried out in every patient suspected of indeterminate and borderline types of leprosy. In superficial mycosis, scrapings were made for mycological examination whenever it was necessary to establish a definite diagnosis. The remainder of the dermatological conditions were clinically diagnosed. No attention was paid to BCG scars in this study.

\section{Results}

100,939 school children were examined. The data relative to age group, sex, clinical forms of leprosy and the principal skin diseases diagnosed are listed in Figure 1 and Table 1.

Table 1. Cases of leprosy according to age group and clinical form diagnosed in the examination of 100,939 children in the State of Amazonas, Brazil, 1979-82.

\begin{tabular}{lcrrrrr}
\hline & \multicolumn{5}{c}{ Clinical form } \\
\cline { 2 - 6 } Age group & Sex & L & I & B & T & Total \\
\hline \multirow{2}{*}{$5-8$} & M & 2 & - & 3 & 6 & 11 \\
& F & 1 & 2 & - & 7 & 10 \\
$9-12$ & M & 6 & 1 & 1 & 14 & 22 \\
& F & 4 & 5 & 3 & 21 & 33 \\
$13-16$ & M & 1 & 2 & 4 & 9 & 16 \\
Subtotal & F & 2 & 2 & - & 11 & 15 \\
& M & 9 & 3 & 8 & 29 & 49 \\
General total & F & 7 & 9 & 3 & 39 & 58 \\
& & 16 & 12 & 11 & 68 & 107 \\
\hline
\end{tabular}




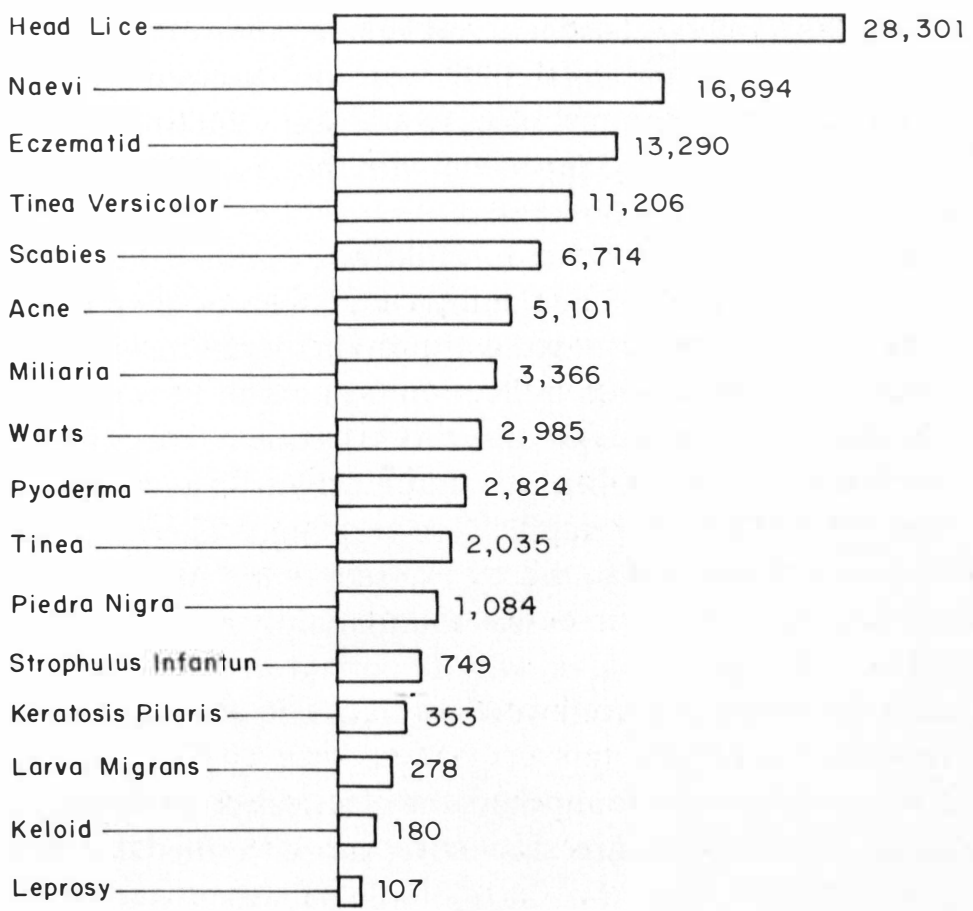

Number of cases of leprosy and other skin diseases

Figure 1. Leprosy and other skin diseases diagnosed in the examination of 100,939 children.

\section{Discussion}

The examination of the school children was planned such that 8 PMWs who previously had no knowledge of dermatology would be trained. Currently these PMWs are able to diagnose the main dermatosis, with a small margin of error, and to diagnose the clinical forms of leprosy. The schools at this moment are being used to train new PMWs and as a strategy in leprosy control. We found the examination of school children to be the best way of training new PMWs in skin diseases other than leprosy. But gradually these PMWs can be employed in the leprosy control programme, which is part of a 'Programa de dermatologia sanitára' that includes leprosy, pemphigus, leishmaniases and STD. In a single month a PMW, medical student or doctor can see hundreds of macules and other lesions that are very important in the diagnosis of the varying types of leprosy.

In order to avoid the problems related to the stigma of leprosy, as well as understand the nosology of skin diseases in school children, we decided to include in this study all the skin diseases found.

Before the medical examination in each school, the PMW, the nurse in charge of the project and a social worker met with the director and the teachers to inform them of the examinations that were to be carried out. One of the reasons to meet 
with the teachers was to instruct them about leprosy and to inform them that the children directed to the outpatients clinic were not necessarily suffering from leprosy, and only in special circumstances would some children not be attending school for a time. We have had no problems with the cases of leprosy found in the schools and the teachers have cooperated.

From the results of the 100,939 school children examined, attention should be drawn to the great numbers of pediculosis and scabies that were diagnosed (Figure 1). The dermatozoonosis were the main dermatosis diagnosed. The results are similar to those verified by Rommiti et al. ${ }^{8}$ in the city of Santos.

Among the superficial mycoses the most frequent was tinea versicolor, contrary to the observations of Bechelli and Curban. ${ }^{3}$ The frequency of facial localization was verified and the results were very high. The percentage of tinea versicolor was smaller than that found by Fonseca et al. ${ }^{5}$ in the same area of the Amazon basin. The dermatophytosis was found mainly in the hair-bearing areas and the most frequent agent isolated was Tricophyton tonsurans. The cases of tinea capitis with the aspect of kerion were not frequent. Piedra nigra is also a very frequent mycosis in this region.

The cases of pitiriasis alba found had the classical distribution: face, upper limbs and trunk. The aspects are similar to those verified by Belliboni and Uagima. ${ }^{4}$

The principal naevi diagnosed were of the melanocytic type, with one case of neurofibromatosis.

The majority of cases of pyoderma were localized in the inferior limbs, associating themselves with scars and hyperpigmented lesions; these lesions were, in most cases, caused by insect bites.

Of the 100,939 schoolchildren examined, 107 were diagnosed with leprosy (Figure 1 and Table 1) and this was the sixteenth highest occurring disease. It is interesting to note the reduced number of indeterminate cases diagnosed, as in this country, it is common to expect a high number of cases to be in this age group. It is possible that the biopsies, systematically performed in all cases suspected to have the clinically suspected indeterminate type leprosy, made this change. It was frequent to find macular lesions and histopathology of tuberculoid type. Two patients with the tuberculoid type of the disease were found to have deformities; one with ulnar clawing of the hand and another with plantar ulcer and drop foot.

\section{Acknowledgment}

We thank Professor René Garrido Neves and Dr S K Noordeen for critical reading of the manuscript. The work was supported, in part, by the German Leprosy Relief Association. 


\section{References}

1 Argolla A, Fraga S, Valle ACF, Prado JC, Ikemoto T. Frequência das dermatoses em estudantes das diversas faculdaded das dermatoses em estudantes das diversas faculdades da UFRJ na cidade universitária (Ilha do Fundao). An Bras Derm, 1974; 49: 1-7.

2 Bechelli LM, Hadad N, Pimenta WP, Pagnano PGM, Melchior E, Fregnan RC, Zanin LC, Arenas A. Epidemiological study of skin diseases in schoolchildren living in Purus Valley (Acre's State, Brazil), in Compendium. XV Congressus Internationalis Dermatologiae, 16-21, Mexicum, 232, 1977.

${ }^{3}$ Bechelli LM, Curban CV. Micoses superficiasis. In Compêndio de Dermatologia, Sao Paulo, Atheneu Editora Sao Paolo S.A., 40 (ed), 1975; 260-2.

${ }^{4}$ Belliboni N, Uagima ME. Estudo epidemiologico da pitiriase alba (casuistica de 300 casos). An Bras Derm, 1977; 50: $135-40$.

5 Fonseca OJM, Castrillon AL, Ferraroni JJ. A pitiriasis versicolor no Estado do Amazonas. Acta Amazonica, 1975; 5: 195-8.

${ }^{6}$ Koticha KK. School surveys in Bombay. Int J Lepr, 1979; 47: 2 (Suppl.), 333.

7 Noussitou FM, Sansarricq H, Walter J. Leprosy in children, WHO, Geneva, 1976.

8 Romiti N, Almeida JRP, Dinato SLM. Recenseamento dermatológico no município de Santos. Especial referência para dermatozoones. An Bras Derm, 1978; 53: 385- 406.

${ }^{9}$ Sehgal VN, Rege VL, Mascarenhas MF, Reys M. The prevalence and pattern of leprosy in a school survey. Int J Derm, 1977; 45: 360-3.

10 Talhari S, Kiesserlich D, Benchaya MV, Alcalde MA. Inquérito epidemiológico sobre hanseníase e outras dermatoses em escolares, Manaus, Estado do Amazonas, Brasil. Med Cut ILA, 1982; 5: 309-12.

\section{LEPROSY CONTROL AND FIELDWORK}

\section{Leprosy in South America}

The following is from the Bulletin of the Pan-American Health Organisation, Volume 20, Number 2, 1986 : Aside from mainland Chile, leprosy is endemic everywhere in the Americas. Although the recording system is deficient and outdated, 318,001 cases were registered in 1984,68\% of them in Brazil. Overall, around 20,000 new cases are reported each year. The largest numbers of cases appear to occur in Argentina, Brazil, Colombia, Mexico, Paraguay, and some Caribbean countries.

Despite important progress in the understanding of leprosy immunity, much of the health staff in many countries is unacquainted with leprosy epidemiology or with leprosy control methods and lacks the means for diagnosing, treating, and monitoring cases. Moreover, the disease is still an object of social stigma in most communities, primarily because appropriate up-to-date information is lacking, and this circumstance hampers leprosy prevention, outpatient treatment, and rehabilitation.

Close to half of the cases diagnosed are contagious forms (lepromatous and dimorphous cases). In Central America the incidence is generally low, ranging from about 0.04 cases per 1,000 inhabitants per year in Guatemala to $0 \cdot 22$ per 1,000 in Costa Rica. Some Caribbean countries (Guyana, Guadeloupe, and Martinique) have relatively high rates - between 2 and 10 cases per 1,000 inhabitants - but the proportion of contagious cases (lepromatous and dimorphous) is lower than in most other countries. In the Amazon area and some parts of the Andes there are foci of high endemicity where the prevalence can reach 30 cases or more per 1,000. The proportions of unspecified and tuberculoid cases vary widely from one country to another, but account for about $20 \%$ and $23 \%$, respectively, of cases in the hemisphere as a whole. In an estimated $30 \%$ of the reported cases the disability involved is of grades II and III.

The current strategy for leprosy control is based on reduction of the sources of infection in the community through early detection of cases and the supervised administration of multidrug treatment. It is also necessary to provide for better implementation of control programmes by making extensive use of the health services network. 


\section{Thalidomide; resumption of distribution by Grünenthal, Germany}

Dr S K Noordeen, Chief Medical Officer, Leprosy, Division of Communicable Diseases, WHO, Geneva, has kindly drawn our attention to new arrangements which have been made by Grünenthal in Germany for the continued distribution of thalidomide, subject to certain conditions. Enquiries must be addressed to Chemie Grünenthal, GMBH, Steinfeldstr. 2, D 5190, Stolberg, Republic of Germany, but the following paragraph from their 'Background Note' summarizes the present situation;

'In response to discussions held with the World Health Organization, which emphasized to us the important role the drug plays in the treatment of the above diseases, it has been decided by the Company to reinstitute the supply of the drug, but only to Governments which will agree to be ultimately responsible for all aspects of its distribution and for any consequences that might occur from any improper use. Grünenthal would of course guarantee that all reasonable measures have been taken to ensure that the supplies of the drug fully meet specifications. Batch analyses of the drug will be performed by Grünenthal in accordance with national GMP requirements and batch certificates conforming to the WHO Certification Scheme willbe supplied at the request of governments.'

\section{Technical Guide for Smear Examination for Leprosy; now in French}

This booklet, originally published in English and now in print for a second (revised) edition, is available in French, from Association Française Raoul Follereau, 31 rue de Dantzig, Paris $15^{\circ}$, France. Thanks are due to Dr Y Le Corroller for a great deal of work in translation and production of this guide.

It is also available in Spanish, Arabic, Thai, Turkish and Bengali. A Portuguese translation has just been completed and steps are being taken to have it translated into Indonesian and Hausa. Enquiries to Karin Rössler, TALMILEP, DAHW, Postfach 348, Wurzburg, West Germany.

\section{A spot test for dapsone in the urine; Han Huikeshoven, Amsterdam}

At the last meeting of TALMILEP in Paris, booklets describing this spot test were distributed and it is now available on enquiry to Ingrid Kalf at the Netherlands Leprosy Relief Association, Wibautstraat 135, 1097 DN, Amsterdam, The Netherlands. It is a 'technical guide for testing patient compliance with dapsone intake in leprosy,' written by the late Han Huikeshoven from the Royal Tropical Institute in Amsterdam.

\section{Essential Drugs Monitor}

The WHO Action Programme on Essential Drugs and Vaccines was started in 1981 to help Member States ensure a regular supply of a selected number of safe and effective medicinal drugs and vaccines of acceptable quality at the lowest possible cost. Especially in developing countries, large segments of the world's population currently have to do without essential drugs, which are either unobtainable in the country, poorly distributed, too expensive or improperly used.

Since 1981, more than 80 countries have drawn up essential drugs lists or started projects in support of primary health care, working with the Action Programme to provide reliable essential drugs and vaccines that: meet real medical needs; have significant therapeutic value; are acceptably saf e; and offer satisf actory value for money.

The Essential Drugs Monitor, the Action Programme's newsletter, was launched in November 1985 to help fill the information gap. It is intended for all individuals and groups working in the essential drugs field, and aims to provide an information link between experiences in different countries. It is published three times a year in Arabic, English, French and Spanish.

Regular features include:

Useful Reading, listing basic literature on selection of drugs, prices, management, quality control, drug usage, legislation and regulatory control, and drug information;

News Desk, reporting on the development of the essential drugs concept and related activities in various regions and countries (the first two issues have reported news from Central America and Panama, the Eastern Mediterranean and the Western Pacific, as well as from Bhutan, Gambia, Islamic Republic of Iran, Nepal, and United Republic of Tanzania);

Published Lately, summarizing new books and reports;

WHO At Large, giving brief news of WHO programmes related to the Action Programme, such as Diarrhoeal Diseases Control, the Expanded Programme on Immunization, and Pharmaceuticals.

In response to enthusiastic demand, the Monitor's print run has been increased to 12,000 copies. For a free copy, please write to: Action Programme on Essential Drugs and Vaccines, World Health Organization, 1211 Geneva 27, Switzerland. 